University of South Florida

DIGITAL COMMONS

Digital Commons @ University of

@ UNIVERSITY OF SOUTH FLORIDA

South Florida

3-21-2017

\title{
The Effect of Behavioral Skills Training on Shot Performance in Field Hockey
}

Kelsey O'Neill

University of South Florida, oneill4@mail.usf.edu

Follow this and additional works at: https://digitalcommons.usf.edu/etd

Part of the Business Administration, Management, and Operations Commons, and the Social and Behavioral Sciences Commons

\section{Scholar Commons Citation}

O'Neill, Kelsey, "The Effect of Behavioral Skills Training on Shot Performance in Field Hockey" (2017). USF Tampa Graduate Theses and Dissertations.

https://digitalcommons.usf.edu/etd/6737

This Thesis is brought to you for free and open access by the USF Graduate Theses and Dissertations at Digital Commons @ University of South Florida. It has been accepted for inclusion in USF Tampa Graduate Theses and Dissertations by an authorized administrator of Digital Commons @ University of South Florida. For more information, please contact digitalcommons@usf.edu. 
The Effect of Behavioral Skills Training on Shot Performance in Field Hockey

by

\title{
Kelsey A. O’Neill
}

\author{
A thesis submitted in partial fulfillment \\ of the requirements for the degree of \\ Master of Arts \\ Department of Child and Family Studies \\ College of Behavioral and Community Sciences \\ University of South Florida \\ Major Professor: Raymond Miltenberger, Ph.D. \\ Kimberly Crosland, Ph.D. \\ Catia Cividini-Motta, Ph.D. \\ Date of Approval: \\ March 10, 2017
}

Keywords: Applied Behavior Analysis, Sports Performance Improvement

Copyright (C) 2017, Kelsey A. O’Neill 


\section{DEDICATION}

This thesis is dedicated to my parents, Peter and Peggy, who have always supported me in every endeavor, even if it means moving thousands of miles away from home. I would also like to dedicate this thesis to my brothers for being my role models and inspirations to play sports. Additionally, I would like to dedicate this thesis to all of my family and friends that have supported me throughout my graduate school experience. Also, I dedicate this thesis to each of my coaches who always believed in the potential I had as a player and a student. 


\section{ACKNOWLEDGMENTS}

I would like to express my gratitude to Dr. Raymond Miltenberger for his guidance and support throughout the completion of my thesis. Additionally, I would like to thank Dr. Miltenberger for his contributions to the field of Applied Behavior Analysis as well as his research on Behavioral Skills Training. I would also like to thank all members of Dr. Miltenberger's research lab for all of their feedback and support each week. 


\section{TABLE OF CONTENTS}

List of Tables $\quad$ ii

$\begin{array}{ll}\text { List of Figures } & \text { iii }\end{array}$

$\begin{array}{lll}\text { Abstract } & \text { iv }\end{array}$

Introduction 1

Method $\quad 5$

Participants and Setting $\quad 5$

Dependent Variable $\quad 5$

Materials 6

Data Collection 6

Interobserver Agreement $\quad 6$

Treatment Integrity $\quad 7$

Social Validity $\quad 8$

Experimental Design and Procedures $\quad 8$

Baseline $\quad 8$

$\begin{array}{lr}\text { Behavioral Skills Training } & 8\end{array}$

$\begin{array}{ll}\text { Results } & 10\end{array}$

$\begin{array}{ll}\text { Discussion } & 12\end{array}$

$\begin{array}{ll}\text { References } & 16\end{array}$

$\begin{array}{ll}\text { Tables and Figures } & 19\end{array}$

Appendices $\quad 24$

Appendix A: 11 Step Task Analysis for Slap Shot 24

Appendix B: 11 Step Task Analysis for Drive $\quad 25$

Appendix C: 13 Step Task Analysis for Sweep 26

Appendix D: Treatment Integrity Checklist $\quad 27$

Appendix E: Social Validity Pre-Intervention Questionnaire 28

Appendix F: Post-Intervention Social Validity Questionnaire 29

Appendix G: Expert Coaches Scoring Form 30 


\section{LIST OF TABLES}

Table 1: $\quad$ Social Validity -Results from post-training social validity questionnaire 19

Table 2: $\quad$ Social Validity -Results from expert coaches scoring forms 20 


\section{LIST OF FIGURES}

Figure 1: $\quad$ Player 1 Results - Results for Player 1's slap shot, sweep, and drive during baseline and intervention

Figure 2: $\quad$ Player 2 Results - Results for Player 2's slap shot, drive, and sweep during baseline and intervention

Figure 3: $\quad$ Player 3 Results - Results for Player 3's drive, slap shot, and sweep during baseline and intervention 


\begin{abstract}
Behavior analysis procedures have been used to improve sports performance and enhance player safety across a wide variety of sports. The current study evaluated the effects of behavioral skills training on three common field hockey hits, a slap shot, drive, and sweep for young field hockey players. The procedures were evaluated in a multiple baseline across behaviors for three players. Results showed increases in each type of shot once intervention was implemented.
\end{abstract}

Keywords: applied behavior analysis, behavioral skills training, sports performance, field hockey, drive, slap, sweep 


\section{INTRODUCTION}

Field hockey is a popular sport among men and women in roughly 122 countries around the world (Murtaugh, 2009). Although it is a recognized sport internationally, there is a lack of behavior analytic research in field hockey. As in most sports, injuries are relatively common in field hockey. According to Murtaugh (2009), when compared to other sports such as basketball and soccer, the rate of injuries in field hockey are similar. While the most common injuries tend to occur on the lower limbs, the second most common injuries occur on the upper limbs and occur at a higher rate in field hockey than other sports (Murtaugh, 2009).

In a review of NCAA field hockey injuries by Dick, Agel, and Vela (2007), concussions and lacerations to the head and face increased significantly between 1988 and 2003. Although there was a decrease in game injuries overall, it is six times more likely that a head injury will occur during a game than during practice. According to Dick et al., nearly $60 \%$ of injuries sustained during games were due to either the stick or ball coming into contact with the head, limbs, or fingers. Within the NCAA Sports Medicine Handbook (2009), it was stated that in comparison to basketball, football, and wrestling, head and face injuries are higher in field hockey. The NCAA also reported that the majority of these injuries were due to raised sticks or elevated balls. In recent years, there has been a push for field hockey players to wear more protective headgear (Kriz et al., 2012). In the fall of 2011, many high school teams enforced a rule requiring protective eyewear for players to wear in an attempt to decrease injuries to the face 
(Kriz et al., 2012). While this rule has yet to make it to the NCAA or international levels, there is still a concern for head injuries sustained by field hockey players.

Aside from protective gear and changes in rules, there are other ways to attempt to decrease the number of injuries that occur in field hockey. Although it is okay to play an elevated ball as long as it is not considered dangerous, unintentionally elevated balls can occur from improper execution of a hit (Kriz et al., 2012). Within the world of athletics, there are some "traditional" coaching strategies that tend to focus on incorrect responses and negative verbal feedback (Seniuk, Witts, Williams, \& Ghezzi, 2013). Typical coaching procedures in field hockey tend to consist of hits being modeled by team members who are considered to have one of the best hits. However, simply watching a model may not be sufficient in learning that skill. Other techniques for teaching skills may be more effective strategies for coaches to utilize.

The application of behavioral principles in sports has been around for nearly four decades. A variety of principles have been evaluated, including but not limited to, behavioral coaching, differential reinforcement, goal setting, verbal feedback, auditory feedback, video modeling, video feedback, and public posting (Anderson, Crowell, Doman, \& Howard, 1988; Fogel, Weil, \& Burris, 2010; Kelley \& Miltenberger, 2016; Komaki \& Barnett, 1977; Luiselli, Woods, \& Reed, 2011; Scott, Scott \& Goldwater, 1997; Wack, Crosland, \& Miltenberger, 2014). Some sports that have been included in the utilization of behavioral principles are football, basketball, tennis, soccer, rugby, ice hockey, and competitive dance. In recent years there has been growth in the research examining the effects of behavioral procedures on sports performance (Luiselli et al., 2011).

In 1977, Komaki and Barnett were the first to examine the concept of behavioral coaching with youth football players in which they evaluated if behavioral coaching would result 
in better performance than traditional coaching. Their procedure consisted of describing plays to players, modeling the accurate responses for players, and giving players feedback on how well they performed during practice. Komaki and Barnett saw that with the use of behavioral coaching, youth football players executed plays more accurately than they did with traditional coaching.

A more recent procedure that has been evaluated for teaching new skills is behavioral skills training (BST). BST is an active learning procedure that has been an effective technique for teaching a variety of skills (Himle \& Miltenberger, 2004; Miltenberger, 2008, 2016). The process consists of instructions, modeling of the target behavior, an opportunity to rehearse the target behavior, and feedback on the rehearsal of the skill (Himle \& Miltenberger, 2004). Results from several studies suggested that when children received BST, they were more likely to correctly implement the safety skills needed when finding a firearm (Gatheridge et al., 2004; Himle, Miltenberger, Gatheridge \& Flessner, 2004; Miltenberger et al., 2009), facing an abduction threat (Johnson et al., 2005, 2006), or finding a dangerous item (Dancho, Thompson, \& Rhoades, 2008; Houvouras \& Harvey, 2014).

Although BST has been shown to be an effective teaching procedure, there is little research on the use of BST and sports performance. Tai and Miltenberger (in press) examined the use of BST for teaching youth football players to tackle properly to avoid head injuries. The researchers examined improper tackling of youth football players and devised a task analysis that defined proper tackling. The researchers first provided instructions and modeled the skills. The participants then repeatedly rehearsed their tackling skills with praise for correct performance and corrective feedback for errors. All participants acquired and maintained their skills at practices throughout the football season and during generalization probes during games. Results 
from this study showed the effectiveness of BST to increase the correct performance of tackling skills and suggests using BST within sports performance can lead to an increase in correct performance of skills. However, even though BST components have been included in behavioral coaching procedures (Komaki \& Barnett, 1977), only one study has evaluated BST for enhancing sports performance. Therefore, it would be beneficial for the field to continue examining the effectiveness of using BST within sports to enhance performance that may lead to injury reduction. The purpose of this study is to evaluate BST with adolescents interested in playing field hockey to increase the correct form of three types of shots. 


\section{METHOD}

\section{Participants and Setting}

The participants of this study consisted of three 15-year-old females. Participants were recruited through a flier posted on a local adult club field hockey Facebook page. Player 1 was a forward with approximately 2 years field hockey experience. Player 2, a 15-year-old attending a local vocational school had no prior exposure to the sport of field hockey. Player 3 was the most experienced of the three participants, a 15 -year-old forward with nearly 8 years of experience.

Sessions were held at the USF Intramural fields, as well as various local parks close to participants' homes. Assessments were conducted on weekdays or weekends depending on player availability. Data were recorded based on task analyses developed for each shot. Participants were chosen based on the number of steps they performed correctly for each hit. All three participants scored less than $60 \%$ during baseline, meeting inclusion criteria to participate.

\section{Dependent Variable}

The dependent variable for this study was the percentage of steps correctly performed in the task analysis for three hits; drive, slap shot, and sweep. A drive in field hockey can be defined as positioning both hands at the top of the stick, swinging the stick backwards perpendicular with your shoulders, then following through forward while striking the ball. A slap shot consists of the left hand at the top and the right hand at the middle of the stick. Then, quickly bring the stick back for a short backswing and follow through hitting the ball. A sweep involves both hands at the top of the stick, while getting low to the ground, as the stick is flat 
against the field. The stick is then brought backwards and swept along the field forward until making contact with the ball. See Appendices A, B, and C for task analyses of the three target behaviors.

\section{Materials}

Materials for this study consisted of field hockey sticks, field hockey balls, cones, and at times a net. A camera on an iPhone 7s was used to record videos for scoring players' hits, as well as researcher implementation of intervention.

\section{Data Collection}

Data were collected over the course of 4 months. Video recording occurred throughout baseline and intervention sessions. Assessment sessions consisted of three repetitions of each skill for each participant during baseline and intervention. During assessment sessions, participants were video recorded performing each skill 15 yards from the goal and were asked "show me your (name of the shot)." The participants did not receive any feedback after each shot during assessment sessions in baseline and intervention phases. The researcher scored each shot from the slow-motion video by recording each step in the task analysis as correct or incorrect, dividing the number of correct steps by the total number of steps, and multiplying by $100 \%$ for the percentage of correct steps. The researcher also scored the number of shots attempted and number of goals scored in the empty net or through cones set up as a goal. During data collection the camera was held so that it was facing the front of the participants.

\section{Interobserver Agreement}

Interobserver agreement was calculated for 33\% of assessment videos. A second observer was trained on each task analysis before viewing the assessment videos. This training consisted of the second observer scoring sample videos that consisted of examples and non-examples of 
each shot performed by the researcher. Prior to viewing the sample videos the second observer was given descriptions about each shot, as well as YouTube videos of the shots being performed by Olympic level players. Once the second observer had watched the YouTube videos and scored the sample videos, scores were sent to the first observer to calculate IOA on the sample videos. After the first training session, IOA was below $80 \%$ so an in-person training was conducted which consisted of the researcher modeling the steps of each task analysis in person for the second observer. The second observer was then given an opportunity to score the sample videos again. Results after the booster training indicated that IOA of the sample videos was between $88-91 \%$, in which the decision to being IOA on assessment videos was made.

The researcher and second observer scored the assessment videos independent of each other. IOA was calculated by dividing the number of steps of agreement between the two observers by the number of steps in the task analysis of each hit. An agreement was recorded when both observers scored a step as correct or both scored a step as incorrect.

For Player 1, IOA was $81 \%$ (range $69-91 \%$ ) overall with $82 \%$ for slap shot, $85 \%$ for drive, and $76 \%$ for sweep. For Player 2, IOA was $88 \%$ (range $69-97 \%$ ) overall with $86 \%$ for slap shot, $88 \%$ for drive, and $90 \%$ for sweep. For Player 3, IOA was $82 \%$ (range $66-94 \%$ ) overall with $84 \%$ for slap shot, $86 \%$ for drive, and $77 \%$ for sweep.

\section{Treatment Integrity}

The researcher was recorded during intervention to ensure correct implementation. A research assistant viewed the videos of the researcher during implementation and scored the number of steps correctly implemented. Scoring consisted of dividing the number of steps executed correctly by the total number of steps on the researcher's checklist for all training videos. The results showed $100 \%$ treatment integrity for $33 \%$ of intervention videos. 


\section{Social Validity}

To measure social validity, a questionnaire was given to each player prior to data collection (see Appendix E). The questionnaire consisted of a Likert scale ranging from 1 (strongly disagree) to 5 (strongly agree) to score how each player felt about the accuracy of her shots prior to training. Once each player completed training she completed a post-training questionnaire that also consisted of a Likert scale ranging from 1 (strongly disagree) to 5 (strongly agree) to score how effective and useful the players found the intervention to be in improving their hits (see Appendix F). The players also had an opportunity to leave additional comments for the researcher on the bottom of the form.

Pre and post treatment videos were shown to expert coaches who were blind to the study. Each coach received two videos per player, consisting of their last video of baseline and their last video of intervention. The expert coaches were not aware of which videos were pre-treatment or post-treatment. The coaches were given a scoring form consisting of a 10-point scale (from completely incorrect to completely correct execution), to evaluate the videos (see Appendix G).

\section{Experimental Design and Procedures}

A multiple baseline across behaviors design was used the evaluated the effect of behavioral skills training on improving field hockey skills.

Baseline. Baseline data were collected during assessments for all participants until stable responding below $60 \%$ occurred. No feedback was provided during baseline assessments.

Behavioral Skills Training. Intervention was presented for one target behavior at a time for each participant and was staggered across target behaviors. Once a player had a consistent increase in one target behavior, implementation for the next target behavior (and then the third target behavior) occurred. First, the researcher described to the player of how each step of the 
task analyses should look. The researcher then used the task analysis to illustrate each step. After describing the steps of the task analysis, the researcher modeled each step in order to show the player how each step of the targeted hit should look. While modeling the behavior, the researcher described each step in the task analysis as it occurred. Once the researcher explained and modeled the task analysis steps for the targeted hit, the player was given the opportunity to complete the steps. Feedback was given to the player after she attempted the shot. The researcher used descriptive feedback to describe the steps the player performed correctly and described which steps she needed to improve from the task analysis and how to improve the steps.

Training sessions ranged from 15 to 30 minutes each week. Once players were demonstrating $100 \%$ scores from the task analysis steps in a training session, the training session ended. The researcher then conducted three assessments of each target behavior after training. No feedback was provided during assessment videos. In the following practice sessions the researcher implemented another BST session as described above. The process was repeated until an immediate and stable effect occurred for the targeted behavior. Intervention was then implemented for the second target behavior and then the third target behavior in the same fashion. 


\section{RESULTS}

Figure 1 displays results for Player 1 in baseline and after implementation of BST for her slap shot, sweep, and drive. In baseline for all shots, scores were consistently below $60 \%$, averaging at $44 \%$ of correct steps executed for slap shot, $32 \%$ for sweep, and $47 \%$ for drive.

When BST was implemented an immediate increase in the percentage of steps performed correctly occurred for all shots with scores averaging at $87.3 \%$ for slap shot, $86 \%$ for sweep, and $94.4 \%$ for drive by the end of intervention. Figure 2 displays results for Player 2 . In baseline for

all shots, scores were consistently below $40 \%$, averaging at $30 \%$ for slap shot, $25 \%$ for drive, and 17\% for sweep. An immediate effect occurred across shots once BST was implemented, increasing the percentage of steps executed correctly to $91 \%$ for slap shot, and $69 \%$ for drive by the end of intervention. Figure 3 displays results for Player 3. Baseline scores for her drive remained consistent at 55\%, while scores for her slap shot and sweep averaged at $49 \%$ at the end of baseline. After BST was implemented, $87 \%$ of steps were performed correctly for drive, $97 \%$ of steps for slap shot, and $83 \%$ of steps for sweep.

The results for percentage of goals made for each shot during baseline and intervention showed that player 1 scored an average of 50\% during baseline and $67 \%$ during intervention for her slap shot, $22 \%$ during baseline and $67 \%$ during intervention for her sweep, and 20\% during baseline and $42 \%$ during intervention for her drive. Player 2 did not score during baseline for any of the three shots. For her slap shot she scored an average of $25 \%$ and for her drive she scored an average of $11 \%$ during intervention. Player 3 scored an average of 50\% during baseline and 53\% 
during intervention for her slap shot, $17 \%$ during baseline and $42 \%$ during intervention for her sweep, and 50\% during baseline and 33\% during intervention for her drive.

Social validity pre-training questionnaire results from Player 1 indicated that she felt neutral in regards to the accuracy of her slap shot, did not feel as though her drive or sweep were accurate, was not confident in her slap shot or sweep, but was confident in her drive. Player 2's pre-training questionnaire indicated that she did not feel as though any of her shots were accurate, and she was not confident about any of her shots. Player 3's pre-training questionnaire indicated that she did not feel as though her slap or sweep were accurate and did not feel confident about either shot, but that she was confident about her drive and that she felt as though it was accurate.

Social validity results showed Players 1 and 3 both reported that they felt as though their shot accuracy had improved, and that they were more confident in all of their shots. Player 1 scored a 4.9, indicating that she strongly agreed on all statements other than her slap shot improvement. Player 1 also stated that she enjoyed receiving the training. Player 3 scored a 5 on all statements and felt strongly that all of her shots had improved, along with accuracy. She also stated that she enjoyed the training sessions and having the opportunity to continue to play field hockey. Player 2 did not report any post-intervention questionnaire responses.

Expert coaches, blind to the study, scored pre-training and post-training videos of each shot for each player. The researcher then reviewed these forms to determine if the raters noticed an improvement pre-treatment to post-treatment. Results from the expert coaches rating forms showed higher scores for post-training videos than pre-training videos, indicating that there was a noticeable improvement in shot performance for each player. 


\section{DISCUSSION}

This study evaluated the effectiveness of BST to increase shot performance for young field hockey players. The results of this study showed an increase in the percentage of steps performed correctly across all shots for each participant. These results suggest that BST is an effective teaching method in a novel sports setting for improving different skills consisting of a slap shot, drive, and sweep. Using an effective procedure to teach proper shot techniques to young athletes is vital to improving shots on goal and has potential to increase number of goals scored. In this study, BST was implemented on an individual basis, however it could be effective in a group setting. Research should evaluate the use of BST with groups of athletes as intervention with groups would be more efficient. Research should also evaluate the use of BST with advanced level players to see if they would derive benefit from the intervention in the same manner the novice players benefitted. Finally, research should evaluate strategies for teaching coaches to implement BST. Teaching coaches how to properly implement BST will make this teaching method more accessible to players to learn proper shot techniques and potentially lead to improvements of shots and goals scored.

The current study is the second to evaluate BST in a sports setting and the first to evaluate the use of behavioral strategies to the sport of field hockey. The results are similar to those reported by Tai and Miltenberger (in press) who showed that BST increased correct tackling skills with youth football players. Although behavioral interventions have been applied to similar sports that involve correct form while taking shots with an implement (e.g., hockey 
stick, golf club) such as performance posting and goal setting techniques in ice hockey

(Anderson et al., 1998) and the use of TAGteach to teach golf swings (Fogel et al., 2010), this is the first study evaluating behavioral procedures for improving shots in field hockey. It shows the effectiveness of BST that involves the systematic sequence of providing instructions, modeling, rehearsal and feedback. Immediate improvements in shot performance were seen once BST was implemented across all shots for each player. Although there were not consistent perfect scores across players or shots, all players were performing the steps at greatly improved levels by the end of training. All players were consistently missing similar steps focusing on their backswing and follow through. For Player 3 specifically, her backswing and follow through for her drive may have been affected by a history of practicing golf outside of field hockey. Although a golf drive is similar to a drive in field hockey, there are differences between the two such that a golf swing requires greater backswing and greater follow through with the golf club. This greater backswing and follow-through are not appropriate in a field hockey drive and it has been suggested that the follow-through of a drive can impact ball direction and speed, which may lead to injuries (Brétigny, Seifert, Leroy, \& Chollet, 2008; Kerr \& Ness, 2006).

Although the results show large increases in the percentage of correct steps in each shot for each participant when BST was implemented, the increases in percentage of shots in goal (shot accuracy) were more modest. This finding may suggest that improvements in shot form may need to be practiced more extensively with the natural reinforcement that comes from making goals for the improvements to result in large improvements in shot accuracy. Additionally, it was noted that for each player the speed and power of their shots showed a noticeable increase throughout the intervention phase. 
One limitation in this study was the variety or quality of grass that the participants experienced. Although artificial turf is the preferred surface to play on, there were no public parks with turf available to use. Players 1 and 2 experienced several different grass surfaces ranging from thick grass to patchy areas with dirt, but once locations that were convenient and had smooth flat grass were located, sessions were held at these locations. Player 3 had all sessions at the same sports complex playing on the same grass each time, which could have played a role in the consistency of her scores.

Another limitation of this study was that the task analyses did not take into account the differences between performing the skills stationary versus at game speed. Breaking down each step according to game-like situations may have led to some differences in the task analyses and the players' ability to perform skills accurately in a game. A third limitation of this study was that the region where the study took place does not have a large field hockey community, which may have impacted the number of participants recruited and quality of the public fields available for practice. This also may have had an impact on interobserver agreement for the skills performed as research assistants and other researchers in the region are not familiar with the sport and the skills being targeted. Although each shot was broken down into simple steps and the observers were trained to discriminate each step when collecting data, individuals with field hockey experience may have viewed the accuracy of steps performed differently than individuals with no field hockey experience.

The results of this study support the application of BST as an effective coaching strategy to teach the correct form of three types of shots to young field hockey players. In this study, BST was implemented with individual students, and thus is not a strategy a coach could easily use when the coach is responsible for the entire team. However, if assistant coaches are present at 
practice, assistant coaches could pull out players and conduct individual BST for 5 or $10 \mathrm{~min}$ and rotate among players. Alternatively the coach could implement the instructions and modeling components of BST with the group and then have individual players rehearse with the other players observing and providing feedback. In this model, the players could be given the opportunity for rehearsal on a rotating basis. In still another option, players could pair up and provide BST with each other. This peer-implemented BST could be facilitated with written task analyses (checklists) to be used for scoring the performance, video clips to train the peers to conduct BST, or pyramidal training in which the coach teaches some players who teach other players. Researchers should investigate these strategies for making BST more accessible and thus more widely used to promote a variety of skills in a variety in sports' settings.

It is also important for researchers to evaluate the social validity of these versions of BST to coaches who would implement them in a variety of sports. Coaches may be more likely to use interventions they find acceptable, they believe will be effective, and they do not think take too much effort or time away from their practices. Research should not only evaluate social validity, but also evaluate ways to make BST more socially valid to enhance the likelihood it will be adopted by coaches in a variety of sports. 


\section{REFERENCES}

Anderson, D. C., Crowell, C. R., Doman, M., \& Howard, G. S. (1988). Performance posting, goal setting, and activity-contingent praise as applied to a university hockey team. Journal of Applied Psychology, 73, 87-95.

Brétigny, P., Seifert, L., Leroy, D., \& Chollet, D. (2008). Upper-limb kinematics and coordination of short grip and classic drives in field hockey. Journal of applied biomechanics, 24, 215-223.

Dancho, K., Thompson, R., \& Rhoades, M. (2008). Teaching preschool children to avoid poison hazards. Journal of Applied Behavior Analysis, 41, 267-271

Dick, R., Hootman, J. M., Agel, J., \& Vela, L. (2007). Descriptive epidemiology of collegiate women's field hockey injuries: National Collegiate Athletic Association Injury Surveillance System, 1988-1989 through 2002-2003. Journal of Athletic Training, 42, 211.

Fogel, V. A., Weil, T. M., \& Burris, H. (2010). Evaluating the efficacy of TAGteach as a training strategy for teaching a golf swing. Journal of Behavioral Health and Medicine, 1, 25-41.

Gatheridge, B. J., Miltenberger, R. G., Huneke, D. F., Satterlund, M. J., Mattern, A. R., Johnson, B. M., \& Flessner, C. A. (2004). Comparison of two programs to teach firearm injury prevention skills to 6-and 7-year-old children. Pediatrics, 114, 294-299.

Himle, M. B., \& Miltenberger, R. G. (2004). Preventing unintentional firearm injury in children: 
The need for behavioral skills training. Education and Treatment of Children, 27, 161177.

Himle, M. B., Miltenberger, R. G., Gatheridge, B. J., \& Flessner, C. A. (2004). An evaluation of two procedures for training skills to prevent gun play in children. Pediatrics, $113,70-77$.

Houvouras, A. J. \& Harvey, M. T. (2014). Establishing fire safety skills using behavioral skills training. Journal of Applied Behavior Analysis, 47, 420-424.

Johnson, B. M., Miltenberger, R. G., Egemo-Helm, K., Jostad, C. M., Flessner, C., \& Gatheridge, B. (2005). Evaluation of behavioral skills training for teaching abduction prevention skills to young children. Journal of Applied Behavior Analysis, 38, 67-78

Johnson, B. M., Miltenberger, R. G., Knudson, P., Egemo-Helm, K, Kelso, P., Jostad, C. \& Langley, L. (2006). A preliminary evaluation of two behavioral skills training procedures for teaching abduction prevention skills to school children. Journal of Applied Behavior Analysis, 39, 25-34.

Kelley, H., \& Miltenberger, R. G. (2016). Using video feedback to improve horseback-riding skills. Journal of Applied Behavior Analysis, 49, 138-147.

Kerr, R., \& Ness, K. (2006). Kinematics of the field hockey penalty corner push-in. Sports Biomechanics, 5(1), 47-61.

Komaki, J. \& Barnett, F. T. (1977). A behavioral approach to coaching football: Improving the play execution of the offensive backfield on a youth football team. Journal of Applied Behavior Analysis, 10, 657-664.

Kriz, P. K., Comstock, R. D., Zurakowski, D., Almquist, J. L., Collins, C. L., \& d'Hemecourt, P. A. (2012). Effectiveness of protective eyewear in reducing eye injuries among high school field hockey players. Pediatrics, 130(6), 1069-1075. 
Luiselli, J. K., Woods, K. E., \& Reed, D. D. (2011). Review of sports performance research with youth, collegiate, and elite athletes. Journal of Applied Behavior Analysis, 44, 9991002.

Miltenberger, R., Gross, A., Knudson, P., Bosch, A., Jostad, C., \& Breitwieser, C. B. (2009). Evaluating behavioral skills training with and without simulated in situ training for teaching safety skills to children. Education and Treatment of Children, 32, 63-75.

Miltenberger, R. (2008). Teaching safety skills to children: Prevention of firearm injury as an exemplar of best practice in assessment, training, and generalization of safety skills. Behavior Analysis in Practice, 1, 30-36.

Miltenberger, R. (2016). Behavior modification: Principles and procedures ( $6^{\text {th }}$ ed). Boston, MA: Cengage Learning.

Murtaugh, K. (2009). Field hockey injuries. Current Sports Medicine Reports, 8, 267-272.

National Collegiate Athletic Association. (2009). 2010 NCAA Sports Medicine Handbook. Indianapolis, IN: NCAA.

Scott, D., Scott, L. M., \& Goldwater, B. (1997). A performance improvement program for an international-level track and field athlete. Journal of Applied Behavior Analysis, 30, 573575.

Seniuk, H. A., Witts, B. N., Williams, W. L., \& Ghezzi, P. M. (2013). Behavioral coaching. The Behavior Analyst, 36, 167.

Tai, S. \& Miltenberger, R. (2016). Evaluating behavioral skills training to teach safe tackling skills to youth football players. Manuscript submitted for publication.

Wack, S. R., Crosland, K. A., \& Miltenberger, R. G. (2014). Using goal setting and feedback to increase weekly running distance. Journal of Applied Behavior Analysis, 47, 181-185. 


\section{TABLES AND FIGURES}

Table 1

Post-Training Questionnaire Results

\begin{tabular}{|c|c|c|c|}
\hline Item & Player 1 & Player 2 & Player 3 \\
\hline Slap shot has improved & 4 & & 5 \\
\hline Drive has improved & 5 & & 5 \\
\hline Sweep has improved & 5 & & 5 \\
\hline Slap shot is more accurate & 5 & & 5 \\
\hline Drive is more accurate & 5 & & 5 \\
\hline Sweep is more accurate & 5 & & 5 \\
\hline More confident in my slap shot & 5 & & 5 \\
\hline More confident in my drive & 5 & & 5 \\
\hline More confident in my sweep & 5 & & 5 \\
\hline I enjoyed training & 5 & & 5 \\
\hline Training would benefit others & 5 & & 5 \\
\hline
\end{tabular}

Note: Scale is 1 (strongly disagree) to 5 (strongly agree) 
Table 2

$\underline{\text { Expert Coaches Scores }}$

\begin{tabular}{lllllll}
\hline & \multicolumn{2}{c}{ Player 1 } & & $\underline{\text { Player 2 }}$ & \multicolumn{2}{c}{$\underline{\text { Player 3 }}$} \\
\cline { 5 - 6 } & BL & BST & BL & BST & BL & BST \\
Slap & 4 & 7 & 2 & 6 & 7 \\
Drive & 4 & 6 & 3 & 6 & 7 \\
Sweep & 5 & 7 & & 5 & 7 \\
\hline
\end{tabular}

Note: Scale is 1 (completely incorrect) - 10 (completely correct) 


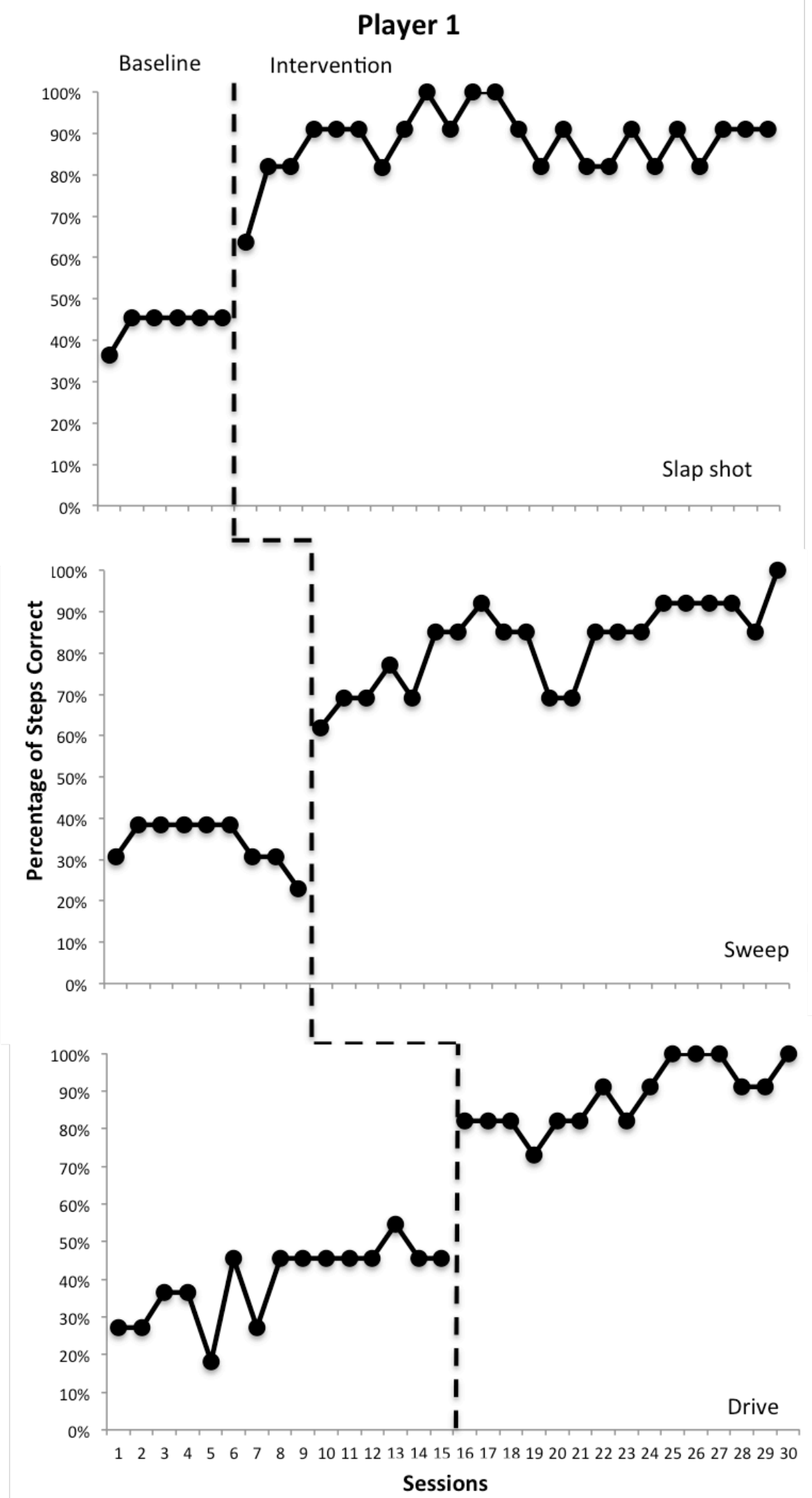

Figure 1. Results for Player 1's slap shot, sweep, and drive during baseline and intervention. 


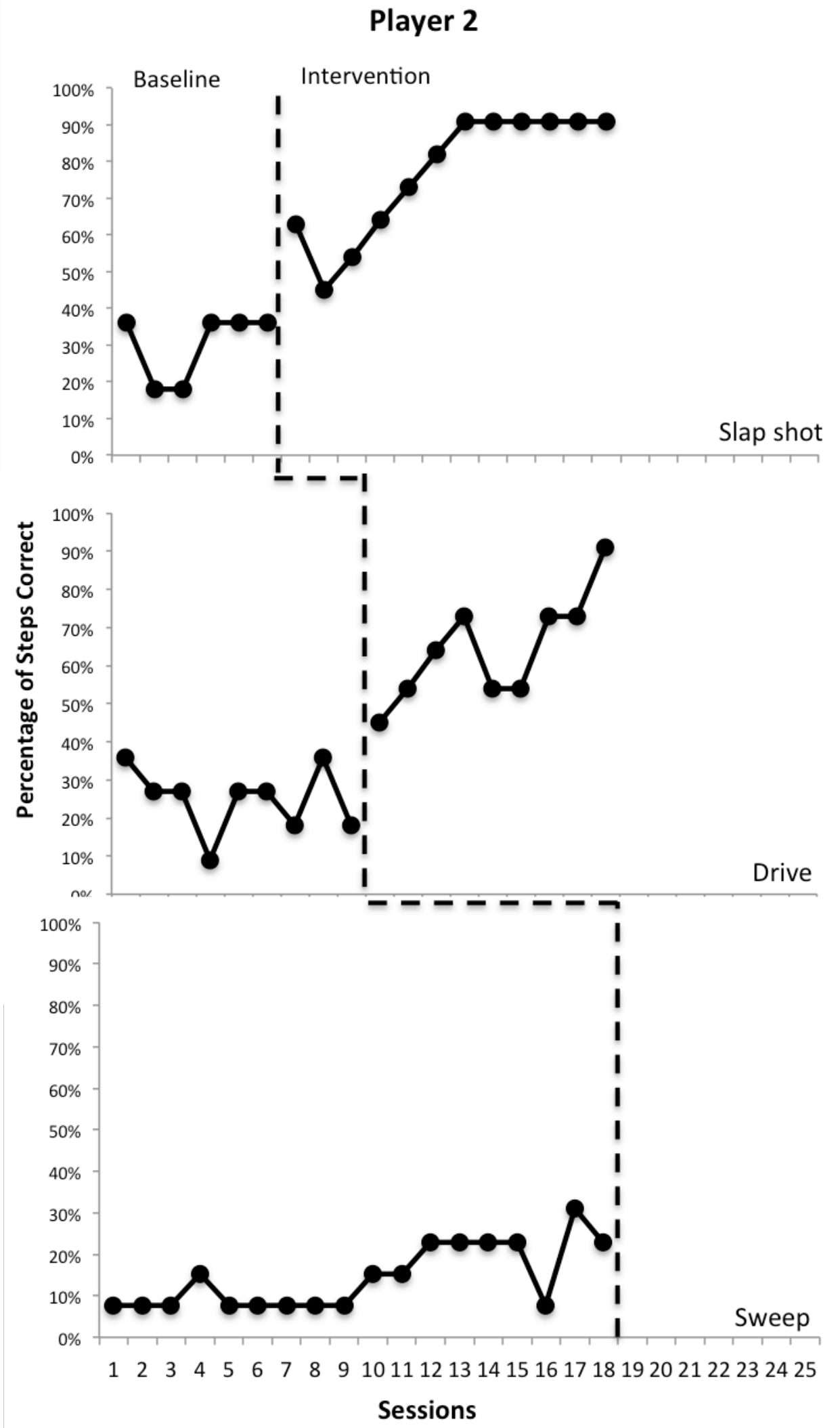

Figure 2. Results for Player 2's slap shot, drive, and sweep during baseline and intervention. 


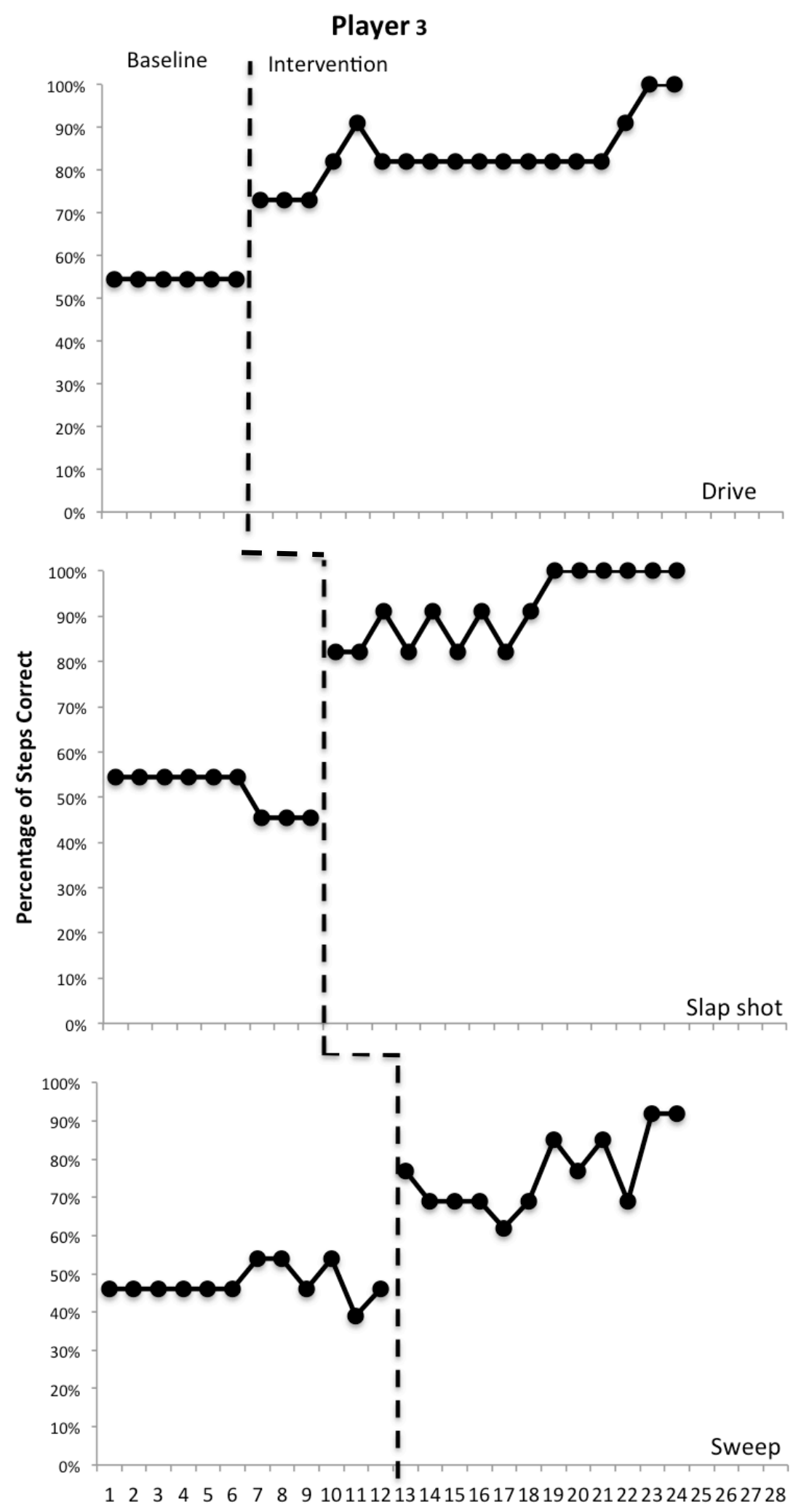

Sessions

Figure 3. Results for Player 3's drive, slap shot, and sweep during baseline and intervention. 


\section{APPENDICES}

11 Step Task Analysis for Slap Shot

\begin{tabular}{|c|c|c|}
\hline \multirow{7}{*}{ Starting Position } & Steps & Description \\
\hline & 1. Feet & Feet together \\
\hline & 2. Knees bent & Knees bent in a half-squat position \\
\hline & 3. Right Hand & Place in the middle of the stick \\
\hline & 4. Left hand & Place at the top of the stick grip \\
\hline & 5. Stick back & Move stick backwards parallel with the hip \\
\hline & 6. Step & $\begin{array}{l}\text { Step laterally with left foot towards target, opening } \\
\text { the hips }\end{array}$ \\
\hline \multirow[t]{3}{*}{ Contact } & 7. Contact & $\begin{array}{l}\text { Bring stick forward quickly as you step, making } \\
\text { contact with the bottom of the ball }\end{array}$ \\
\hline & 8. Post contact & $\begin{array}{l}\text { After contact is made with ball continue forward } \\
\text { motion with stick }\end{array}$ \\
\hline & 9. Follow through & $\begin{array}{l}\text { Stop with stick at shoulder height and pointing in } \\
\text { the direction of the target }\end{array}$ \\
\hline \multirow[t]{2}{*}{ Finish } & 10. Support & $\begin{array}{l}\text { Open hips in direction of hit, moving right leg } \\
\text { forward to begin running towards play }\end{array}$ \\
\hline & 11. Ball distance & $\begin{array}{l}\text { Contact with ball was strong enough to send ball } \\
\text { over the end line (at least } 15 \text { yards) }\end{array}$ \\
\hline
\end{tabular}


Appendix B

11 Step Task Analysis for Drive

\begin{tabular}{l|l|l}
\hline Starting Position & $\begin{array}{l}\text { 1. Feet } \\
\text { 2. Knees bent } \\
\text { 3. Hands }\end{array}$ & $\begin{array}{l}\text { Feet together } \\
\text { Knees bent in a half-squat position } \\
\text { Place both hands together at the top of the grip on } \\
\text { the stick } \\
\text { Swing stick back until parallel with shoulder } \\
\text { height } \\
\text { Step laterally with left foot towards target, opening } \\
\text { the hips } \\
\text { Keep head down, keeping eye on the ball through } \\
\text { contact } \\
\text { Bring stick forward quickly as you step, making } \\
\text { contact with the bottom of the ball } \\
\text { After contact is made with ball continue forward } \\
\text { motion with stick } \\
\text { Stop with stick at shoulder height and pointing in } \\
\text { the direction of the target } \\
\text { Open hips in direction of hit, moving right leg } \\
\text { forward to begin running towards play } \\
\text { Contact with ball was strong enough to send ball } \\
\text { over the end line (at least 15 yards) }\end{array}$ \\
Finish & 6. Head & 7. Contact \\
9. Follow through & 10. Support & 11. Ball distance
\end{tabular}


Appendix C

13 Step Task Analysis for Forward Sweep

\begin{tabular}{|c|c|c|}
\hline \multirow{8}{*}{ Starting Position } & Steps & Description \\
\hline & 1. Feet & Feet together \\
\hline & 2. Knees bent & Knees bent in a full-squat position \\
\hline & 3. Hands & Place both hands together at the top of the grip on \\
\hline & 4. Lunge & Lunge forward toward ball with left leg \\
\hline & 5. Stick & Place stick parallel on the ground with knuckles \\
\hline & 6. Line up & Have stick in line with right leg \\
\hline & 7. Sweep & Forcefully sweep stick forward along the turf \\
\hline \multirow[t]{4}{*}{ Contact } & 8. Whip & $\begin{array}{l}\text { Whip upper body around from right to left as stick } \\
\text { is sweeping on the turf }\end{array}$ \\
\hline & 9. Contact & Make contact with the ball \\
\hline & 10. Follow through & $\begin{array}{l}\text { After contact is made with ball continue forward } \\
\text { motion with stick along turf }\end{array}$ \\
\hline & 11. Follow Through & $\begin{array}{l}\text { Stop with stick still on turf after making a semi- } \\
\text { circle on the ground with stick }\end{array}$ \\
\hline \multirow[t]{2}{*}{ Finish } & 12. Support & $\begin{array}{l}\text { Push off of left foot to propel forward and run } \\
\text { towards the direct of play }\end{array}$ \\
\hline & 13. Ball distance & $\begin{array}{l}\text { Contact with ball was strong enough to send ball } \\
\text { over the end line (at least } 15 \text { yards) }\end{array}$ \\
\hline
\end{tabular}




\section{Appendix D}

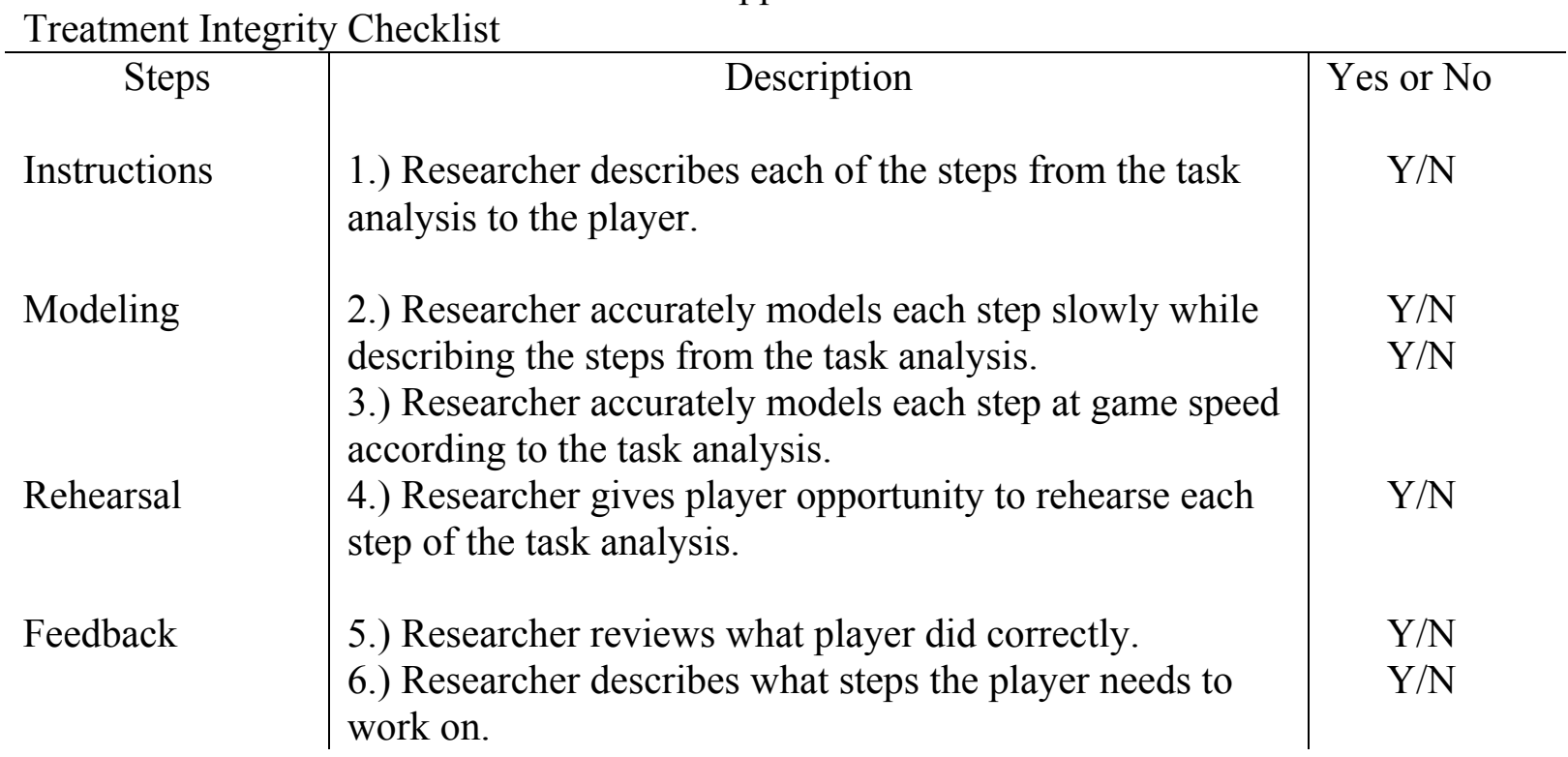


Appendix E

Social Validity Pre-Intervention Questionnaire Question

1.) I feel that my slap shot is accurate.

2.) I feel that my drive is accurate.

3.) I feel that my forward sweep is accurate.

4.) I am confident in my slap shot

5.) I am confident in my drive.

6.) I am confident in my forward sweep.

\begin{tabular}{|ccccc}
$\begin{array}{c}\text { Strongly } \\
\text { Disagree }\end{array}$ & Disagree & Neutral & Agree & $\begin{array}{c}\text { Strongly } \\
\text { Agree }\end{array}$ \\
1 & 2 & 3 & 4 & 5 \\
1 & 2 & 3 & 4 & 5 \\
1 & 2 & 3 & 4 & 5 \\
1 & 2 & 3 & 4 & 5 \\
1 & 2 & 3 & 4 & 5 \\
1 & 2 & 3 & 4 & 5 \\
& & & &
\end{tabular}

Additional comments: 


\section{Appendix F}

Post-Training Social Validity Questionnaire Question

1.) After this training, I feel that my slap shot has improved.

2.) After this training, I feel that my drive has improved.

3.) After this training I feel that my forward sweep has improved.

4.) After this training, I feel that my slap shot is more accurate.

5.) After this training, I feel that my drive is more accurate.

6.) After this training, I feel that my forward sweep is more accurate.

7.) After this training, I am more confident in my slap shot.

8.) After this training, I am more confident in my drive.

9.) After this training, I am more confident in my forward sweep.

10.) I enjoyed receiving this training.

11.)I feel that this training could be beneficial to others.

\begin{tabular}{|c|c|c|c|c|}
\hline $\begin{array}{l}\text { Strongly } \\
\text { Disagree }\end{array}$ & Disagree & Neutral & Agree & $\begin{array}{c}\text { Strongly } \\
\text { Agree }\end{array}$ \\
\hline 1 & 2 & 3 & 4 & 5 \\
\hline 1 & 2 & 3 & 4 & 5 \\
\hline 1 & 2 & 3 & 4 & 5 \\
\hline 1 & 2 & 3 & 4 & 5 \\
\hline 1 & 2 & 3 & 4 & 5 \\
\hline 1 & 2 & 3 & 4 & 5 \\
\hline 1 & 2 & 3 & 4 & 5 \\
\hline 1 & 2 & 3 & 4 & 5 \\
\hline 1 & 2 & 3 & 4 & 5 \\
\hline 1 & 2 & 3 & 4 & 5 \\
\hline 1 & 2 & 3 & 4 & 5 \\
\hline
\end{tabular}

Additional comments: 


\section{Expert Coaches Scoring Form}

\section{Appendix G}

The intent of this evaluation is to get your opinion on how well this individual performs this skill.

Please rate how you feel the quality of this skill is being performed.

How well was the shot executed?

$\begin{array}{llllllllll}1 & 2 & 3 & 4 & 5 & 6 & 7 & 8 & 9 & 10\end{array}$
Completely
Completely
Incorrect
Correct

Please elaborate on your reasoning for the score you have given for each video: 